\title{
Damage Detection in Ceramic Materials Using Bicoherence Analysis
}

\author{
O. AKGUN
}

\begin{abstract}
In this study, Bicoherence method was applied to analyze the state of 6 ceramic plates made from the same material is cracked or not. Of all six plates, while 1 consisted of an undamaged plate, the other 5 comprised of cracked plates. Cracks in damages plates have non-identical deformations. The centre points of the plates were applied to shock at equal severity by means of the pendulum. The sound, which emerged as a result of the impact, was recorded and transferred to the data processing environment. A single bicoherence peak was observed at the centre of the durable plate and more than one peak was seen in the cracked plates by the analysis conducted, in addition, their magnitudes were so much smaller than those of durable plates. While large rising magnitudes were formed at the centre on the bi-coherence plane of the durable ceramic plate, more than one bicoherence peaks, with low magnitudes, were formed on the cracked ceramic plates. Differentiation and feature extraction can clearly be identified in the feature diagonal slice analysis of the cracked plates with the bicoherence analysis carried out. While maximum bicoherence coordinates were formed in the coordinate centre of the durable ceramic plate, deviation from the centre presented itself in the cracked ceramic plates.
\end{abstract}

Index Terms - Acoustic vibration method, Bicoherence, Ceramic Plate, Crack Analysis.

\section{INTRODUCTION}

$\mathrm{C}$ Ceramic materials were acquired from the inorganic components and their raw materials consist of clay and its derivatives [1]. Nowadays, ceramic materials are frequently used in industrial and structural product applications [1,2]. They take shape by applying heating and cooling processes during the production stage. They display demeanour hard, brittle, chemically corrosion-resistant, and insulating in terms of electrical and thermal features [3,4]. They are also resistant to high temperatures, lighter than other materials and their raw materials are plentifully and economically found in nature $[1,2,5]$. In addition to all these advantages, ceramic materials gain brittleness due to baking processes. Cracking and

OMER AKGUN, is with Department of Computer Engineering University of Marmara, Istanbul, Turkey,(e-mail: oakgun@ marmara.edu.tr).

iD https://orcid.org/ 0000-0003-3486-2197

Manuscript received June 12, 2020; accepted Oct 28, 2020.

DOI: $10.17694 /$ bajece. 814401 breakage are their most important drawback due to this feature. Their electrical and thermal insulation is high, chemically stable and has high melting temperatures. However, the provision of raw materials is easy and economical, they also have low production costs and their usage and processing are quite easy [3-7].

The biggest risks in ceramic production are deformations and cracks as a result of improper stacking and storage of ceramic materials. These deformations and cracks cannot be distinguished when covered by enamel and they only turn into marketing problems with feedbacks by users. Many markerbased different methods are being used in the determination of micro-cracks and deformations occurring in ceramics $[1,8,16]$. Mark-based works, used by developing an acoustic measurement method, have been quite effective in determining deformations [1-4]. In this study, data, taken from the measurement system developed by Akinci [1], were analyzed by using the bicoherence method.

\section{EXPERIMENTAL MEASUREMENT AND DATA COLLECTION SYSTEM}

Testing set, developed by Akinci [1], was used in this study and the data were obtained from this testing set. The pendulum was used in order to produce an impact on experimental measurement and data collection systems [1,12]. The experimental application was designed within the framework of the analysis of sound resulting from a pulse effect. The pendulum in the pendulum was collected and recorded by the sound data acquisition system spreading to the environment as a result of the impact on the ceramic plate $[1-4,17,18]$.

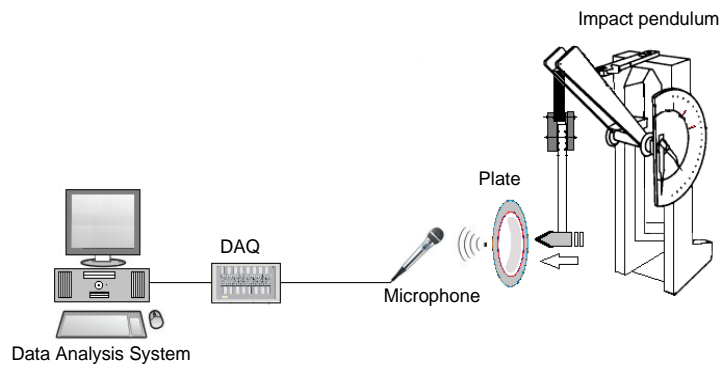

Fig.1. Data acquisition and measurement systems [1-4]

The POE 2000 type Impact Pendulum was used in the experimental data collection system. Impacts in the same 
severity were applied to the ceramic plates of the same type and model through pendulum and the sound data, which emerged as a result of the impact, had been recorded. The output audio signal of the amplifier is transmitted to the computer at a sampling rate of 0.00001 seconds via Advantech $1716 \mathrm{~L}$ Multifunction PCI card and data processing is performed by using Matlab (C) (Fig. 1) [1-4,18].

\section{BI-COHERENCE}

The phase relationships between frequency components are not taken into consideration in signal processing techniques which utilize from second-order statistics and/or power spectrum. Therefore, these techniques are blind against the phase information. Also, the second-order statistics and power spectrum are not enough to define the non-Gaussian process completely in terms of statistics. In recent years, studies on high-order statistics and power spectrum have been conducted in order random processes to be defined more delicately and phase information to be processed [19].

The second-order statistics, like autocorrelation and power spectrum, are quite effective in the analysis of gauss, static and linear processes. The higher-ordered statistics are used in the examination of gauss, static and non-linear processes and in the attainment of significant results. In other words, a random process, like Gaussian distribution $\mathrm{X}(\mathrm{n})$, can be completely defined by autocorrelation function (ACF). ACF is not enough for non-Gaussian processes. Therefore, more information can be obtained from these processes with HOS. While the first-degree torque was given in Equation (1), the second-degree torque and autocorrelation were given in Equation (2) [19,20].

$$
\begin{gathered}
m_{X}=E(X), \sigma_{X}^{2}=E\left[\left(X-m_{X}\right)^{2}\right] \\
m_{X}^{2}(i)=E\{X(n) . X(n+i)\}
\end{gathered}
$$

The higher-ordered statistics can be found by calculating with higher degree torques like $(\mathrm{m} 3, \mathrm{~m} 4 \ldots)$. The non-linear combinations of these higher degree torques can be defined as (c1, c2, c3...) cumulant. The third-level torques were given in Equation 2. The collective equation for the zero-mean process was given in Equations 4,5 and 6 [20].

$$
\begin{aligned}
& m_{X}^{3}(i, j)=E\{X(n) \cdot X(n+i) \cdot X(n+j)\} \\
& c^{2}(i)=m(i) \\
& c^{3}(i, j)=m(i, j) \\
& c^{4}(i, j, k)= \\
& m^{4}(i, j, k)-m^{2}(i) \cdot m^{2}(j, k)-m^{2}(j) \cdot m^{2}(i, k)-m^{2}(k) \cdot m^{2}(i, j)
\end{aligned}
$$

Torques provide more accurate results in the analysis of deterministic signals, whereas cumulative provides more accurate results in the analysis of random signals. If the power spectrum of random signals is defined by DFT in Equation (7);

$$
P_{2}^{x}(f)=D F T\left(C_{2}^{x}(m) \cdot e^{-j 2 \pi m f}\right.
$$

Bispectrum reveals signals resulting from the non-linear process in addition to suppressing Gaussian probability distribution of events. The cumulative spectrum of $3^{\text {rd }}$ degree is called bispectrum and is shown in Equation (8). The signal is real-valued stationary random process is shown as follows $[21,22]$.

$$
\begin{array}{r}
B^{x}\left(f_{1}, f_{2}\right)=\sum_{m=-\infty}^{\infty} \sum_{n=-\infty}^{\infty} C_{3}^{x}(m, n) \cdot e^{-j 2 \pi\left(m f+n f_{2}\right)} \\
B\left(w_{1}, w_{2}\right)=X\left(w_{1}\right) \cdot X\left(w_{2}\right) \cdot X^{*}\left(w_{1}+w_{2}\right)
\end{array}
$$

Unlike the power spectrum, in addition to presenting information on non-linear or gauss distributed non-indicated data, bispectrum also provides the phase information of the sign as an important feature. Peaks in bispectrum show frequency components and phase overlap in the signal. While peaks with two same frequencies show the frequency components in the signal, peaks with different frequencies indicate that there is a phase conflict in these frequencies. For the special case in which w1 and w2 are equal, the diagonal slices (DS) of one-variable bispectrum is given in Equation (10) $[21,24]$.

$$
B(w)=X^{2}(w) \cdot X^{*}(2 w)
$$

The system, which was located between input and output signals of the coherence, has linearity deviation measurement, it is a size based on the calculation of a cross-spectrum and two auto-spectra and is shown as in Equation (11). Bicoherence is the energy ratio of a single sign-on any two frequencies. In other words, it is the quadratic normalized version of the bispectrum. It can be expressed by Equation (12) $[21,24]$.

$$
\begin{gathered}
C_{X Y}(f)=\frac{\left|P_{x y}(f)\right|^{2}}{P_{x x}(f) P_{y y}(f)} \\
\operatorname{Bic}\left(f_{1}, f_{2}\right)=\frac{B\left(f_{1}, f_{2}\right)}{\sqrt{P\left(f_{1}\right) P\left(f_{2}\right) P\left(f_{1}+f_{2}\right)}}
\end{gathered}
$$

\section{APPLICATION OF METHODS}




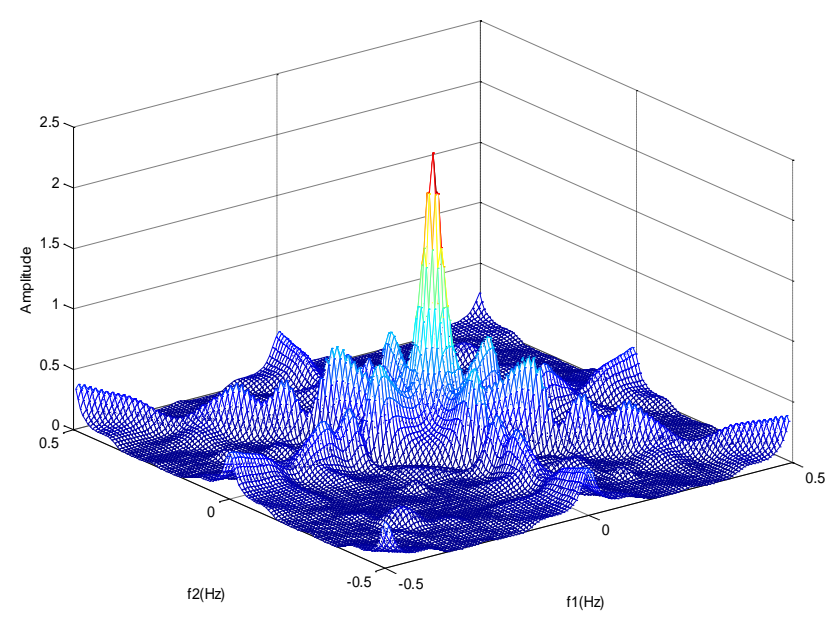

a)

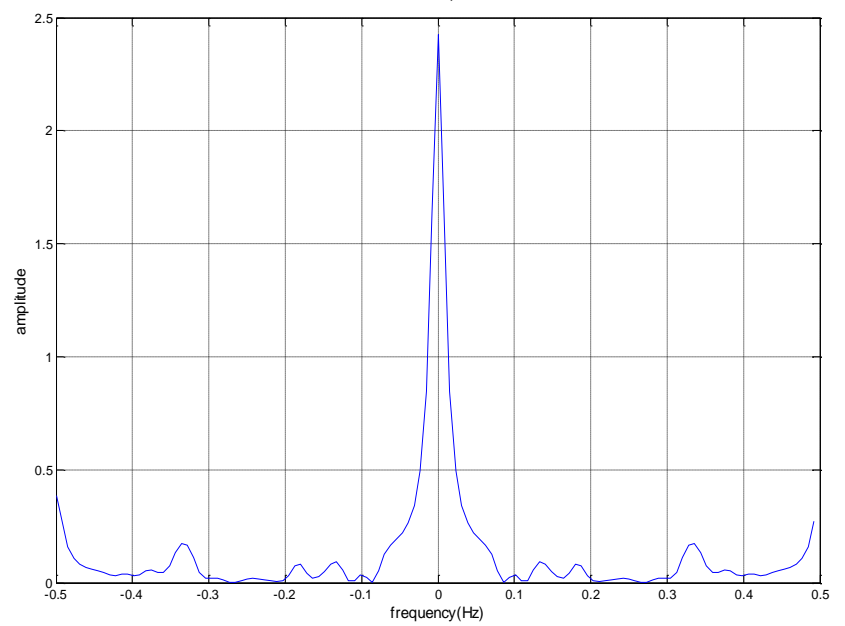

b)

Fig.2. Durable plate a) bicoherence b) diagonal slice graphics

The only one salient peak was observed in durable ceramic material and maximum bicoherence peak is in the magnitude size of $\operatorname{bic}(0,0)=2.4263$. According to this, other fairly small peaks are scattered on the surface (Figure2a). This case is also clearly observed in diagonal slice (Fig.2b).

As can be seen in Figure 3, the unrelatedness is increased around -0.3 and +0.3 in the analysis conducted for the damaged ceramic plate. In other words, distinctive features can be seen to increase. This case appears to be different from the durable ceramic material.

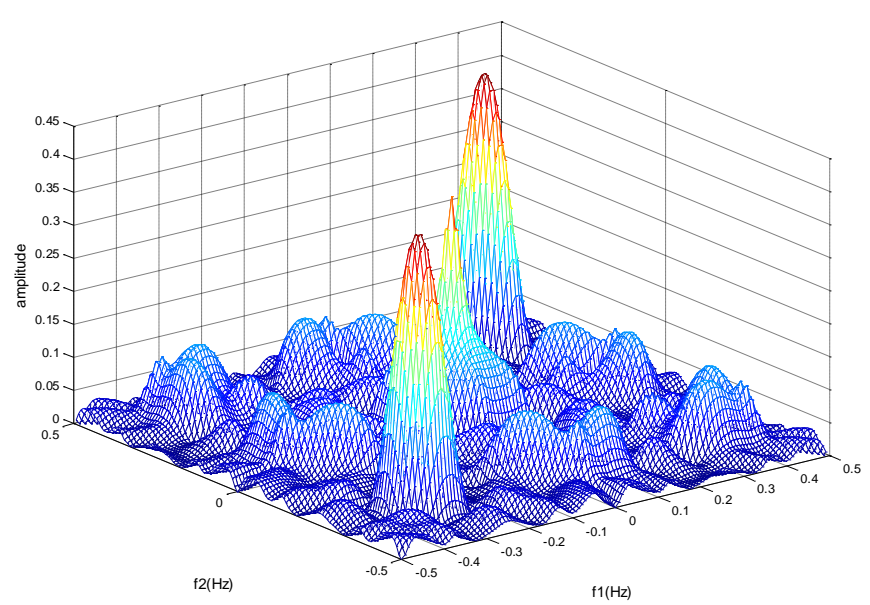

a

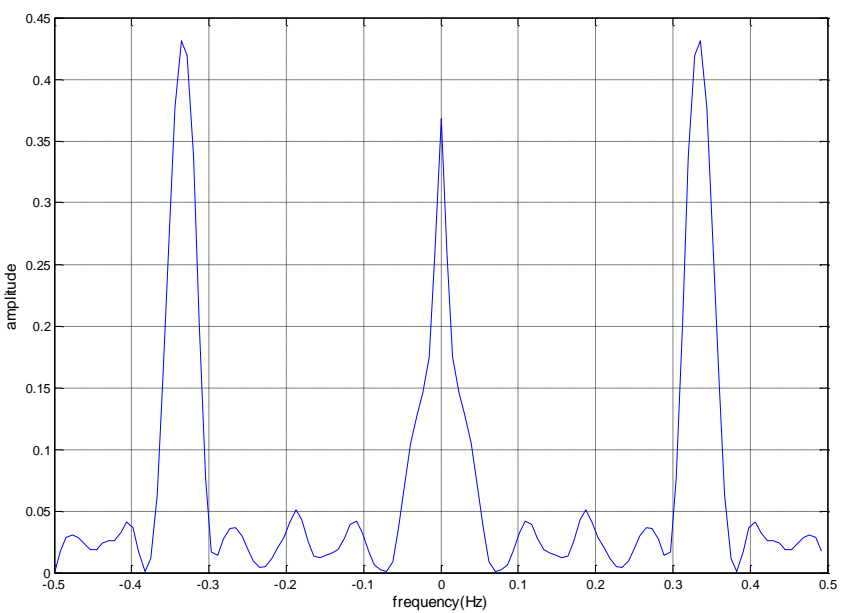

b)

Fig.3. Damaged plate 1 a) bicoherence b) diagonal slice graphics

The centrally-spreading bicoherence peak and two bicoherence peaks bigger in size can be observed in this damaged ceramic material. Maximum bicoherence size is in the coordinates of $\operatorname{bic}(-0.33594,-0.33594)=$ 0.43121(Fig.3a,b). 


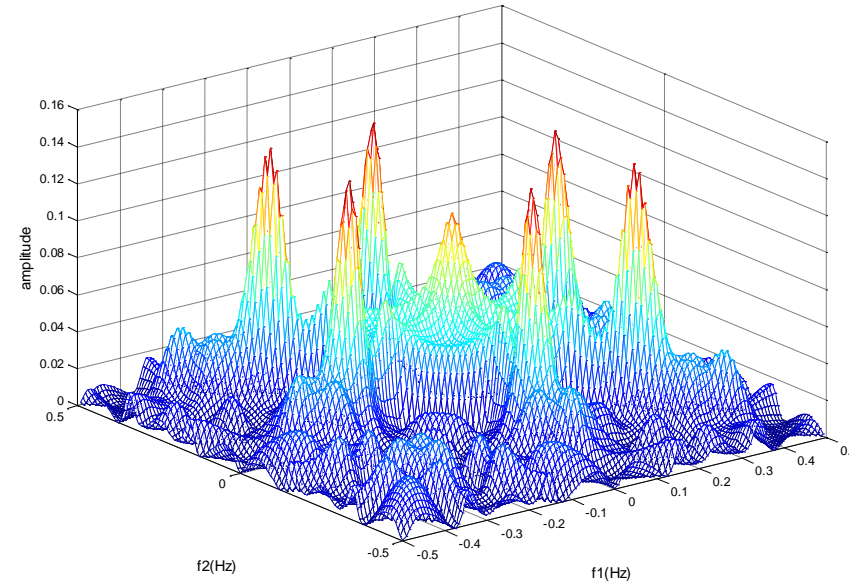

a)

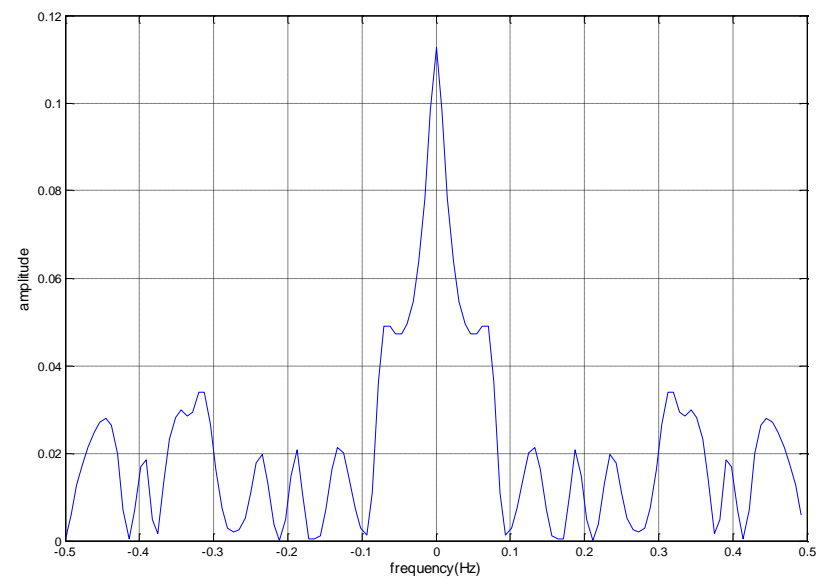

b)

Fig.4. Damaged plate 1 a) bicoherence b) diagonal slice graphics

Bicoherence peak, which spreads in the state of two different peaks, and 6 larger bicoherence peaks around can be observed at the centre for other damaged ceramic material and maximum bicoherence value is in the size of $\operatorname{bic}(0,-0.24219)=$ 0.14369 (Figure4a). There are a maximum and two adjacent peaks at the centre in diagonal slice and there are also peaks in high frequencies and in smaller magnitudes (Fig.4b).

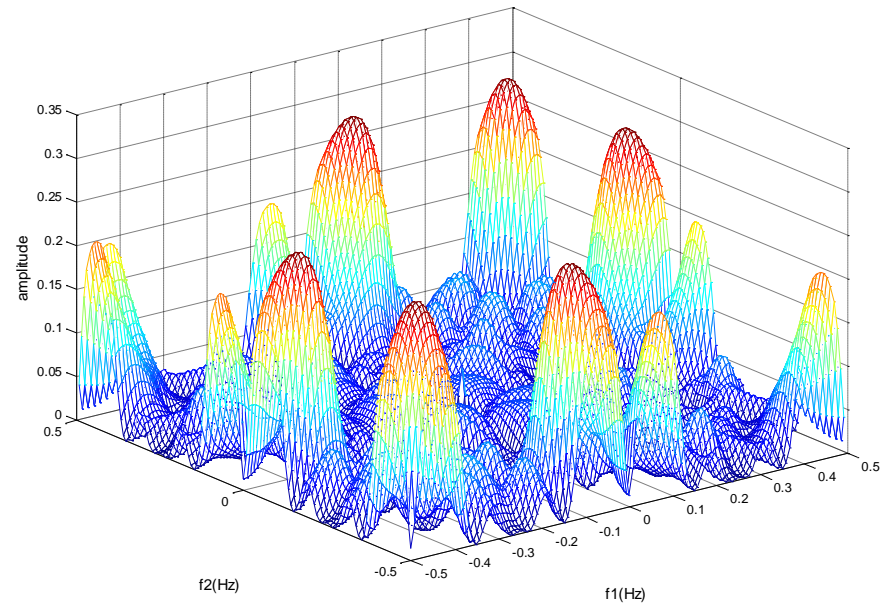

a)

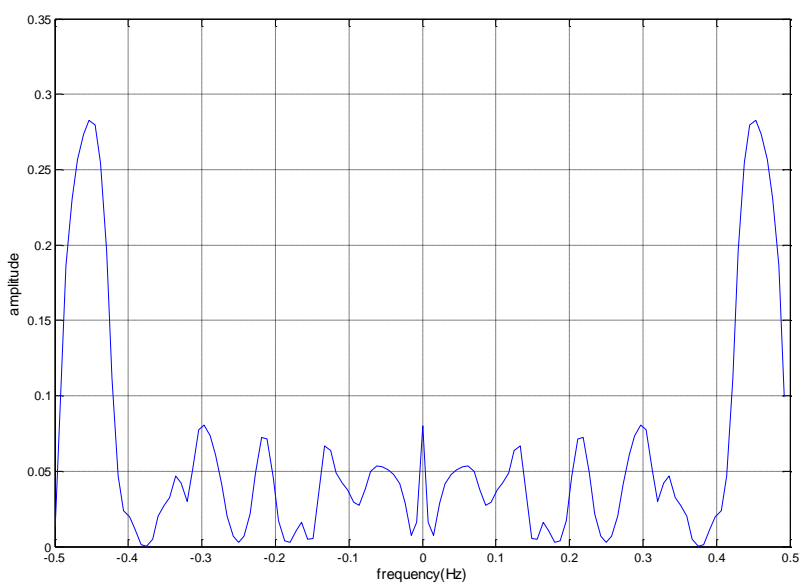

b)

Fig.5. Damaged plate 1 a) bicoherence b) diagonal slice graphics

This example emphasizes bicoherence peaks observed at high frequencies and still, two peaks in the diagonal slice draw attention at high frequencies (Fig.5a, b). Maximum bicoherence is bic $(-0.45313,-0.45313)=0.2827$. 


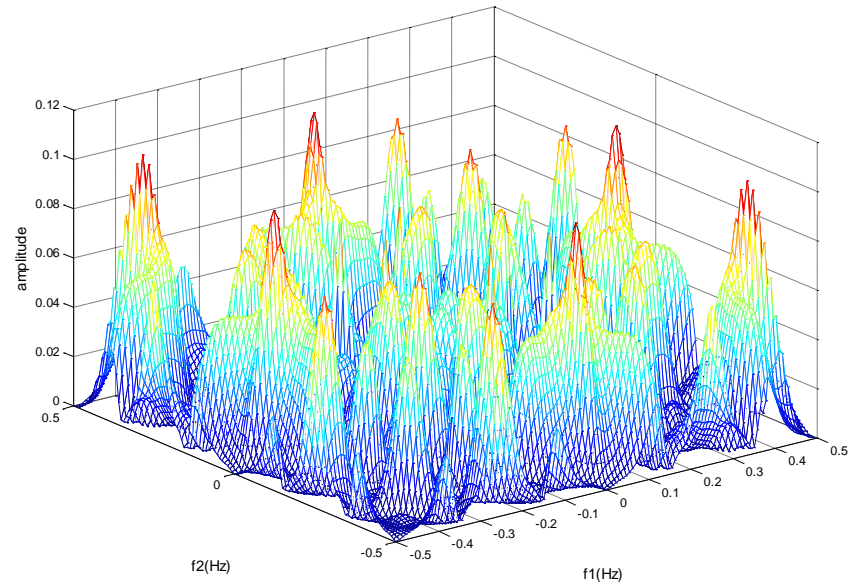

a)

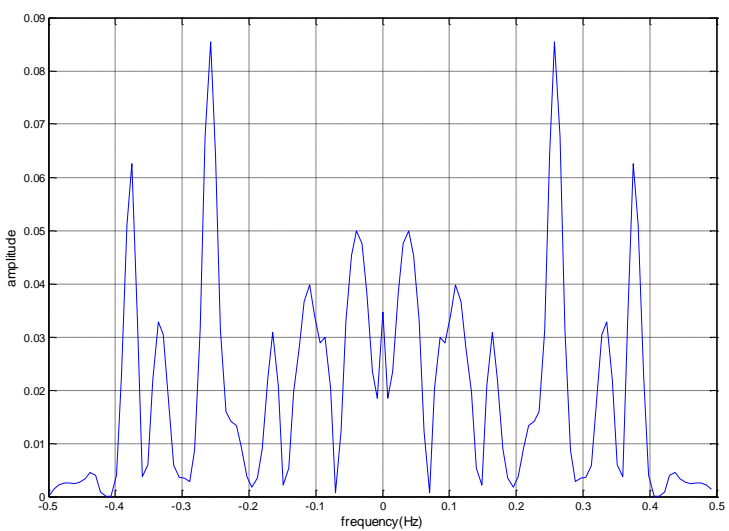

b)

Fig.6. Damaged plate 1 a) bicoherence b) diagonal slice graphics

This damaged ceramic material contains numerous bicoherence peaks (Fig.6a). The same case can also be observed in diagonal slice including 4 large peaks and other smaller peaks (Figure 6b). Maximum bicoherence is bic $(0,-$ $0.40625)=0.10309$.

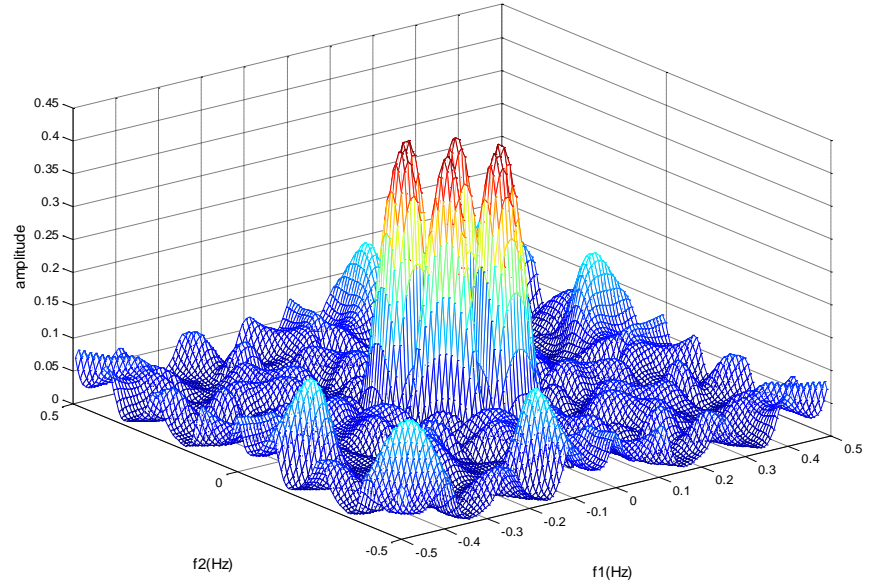

a)

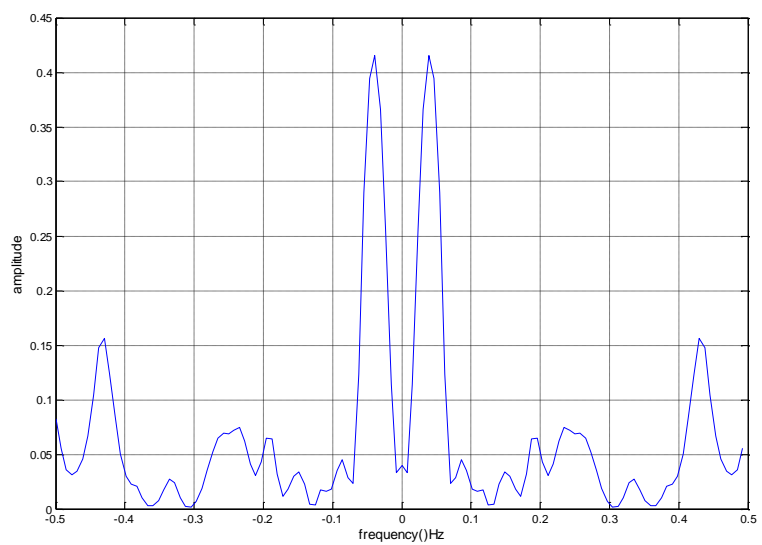

b)

Fig.7. Damaged plate 1 a) bicoherence b) diagonal slice graphics

The final damaged plate example consists of 4 bicoherence peaks (Figure 7a). Two large diagonal peaks can be seen in the diagonal slice (Fig.7b). Maximum bicoherence was calculated as $\operatorname{bic}(0.039063,-0.078125)=0.41517$. 


\section{TABLE I \\ MAXIMUM BICOHERENCE COORDINATES AND MAGNITUDES OF PLATES}

\begin{tabular}{|c|c|c|}
\hline $\begin{array}{c}\text { Ceramic } \\
\text { Material }\end{array}$ & Max. Bic.Coordinates & $\begin{array}{c}\text { Max. Bic. } \\
\text { Magnitudes }\end{array}$ \\
\hline Durable & $(0,0)$ & 2,4263 \\
\hline Damaged 1 & $(-0.33594,-0.33594)$ & 0,43121 \\
\hline Damaged 2 & $(0,-0.24219)$ & 0,14369 \\
\hline Damaged 3 & $(-0.45313,-0.45313)$ & 0,2827 \\
\hline Damaged 4 & $(0,-0,40625)$ & 0,10309 \\
\hline Damaged 5 & $(0,039063,-0,078125)$ & 0,41517 \\
\hline
\end{tabular}

\section{CONCLUSION}

In this experimental study, the durability and crackness of ceramic plates were determined by using the bi-coherence analysis method. 6 same types of ceramic plates were used in the study. Of the plates used in the study, one of the plates was selected from durable plates for controlling purposes and the other 5 damaged plates were selected from the cracked plates. This study is the product of a project study which determines damages in ceramic plates by using an acoustic method. In the analysis, the impact was applied at the centre points of ceramic plates by using a pendulum and the sound occurred as a result of the impact, was analyzed by the data collection system. When analyzing the sound data obtained from the experimental data collection system, one bicoherence peak, with rising large magnitude, was observed at the centre on the bicoherence plane of the durable plate. More than one bicoherence peaks were formed in cracked ceramic plates and their magnitudes were quite smaller compared to those of durable plates (Table 1). While maximum bicoherence coordinates were formed at the coordinate centre in the durable material, deviation from the centre can be observed in damaged material (Table 1). These features can also be observed in two-dimensional diagonal slices in a simple way. The study can be considered quite determinative for distinguishing the state of durability and crackness of the ceramic plates.

\section{REFERENCES}

[1] T.C. Akinci, "The Defect Detection in Ceramic Materials Based on Time-Frequency Analysis by Using the Method of Impulse Noise" Archives of Acoustics, Vol.36, No.1, 2011, pp.1-9.

[2] T.C. Akinci, H.S. Nogay, O. Yilmaz, "Application of Artificial Neural Networks for Defect Detection in Ceramic Materials Archieves of Acoustics", Vol. 37, No.3, 2012, pp.279-286.
[3] T.C. Akinci, S. Seker, R. Gurbuz, E. Guseinoviene, E., "Spectral and Statistical Analysis for Ceramic Plate Specimens Subjected to Impact", Solid State Phenomena .199, 2013, pp.621-626.

[4] O. Akgun, T.C. Akinci, H.S. Nogay, S. Seker, "The defect detection in ceramic materials based on wavelet analysis by using the method of impulse noise", JVE Journal of Vibroengineering, Vol.15, No.2, 2013, pp.818-825.

[5] L. Montanaro, N. Bianchini, J.Ma Rincon, M. Romero, "Sintering Behaviour of Pressed Red Mud Wastes from Zinc Hydrometallurgy", Ceram. Int., 27, 2001, pp. 29-37.

[6] M. Romero, J. Ma Rincón, S. Musik, V. Kozhukharov, "Mössbauer Effect and X-ray Distribution Function Analysis in Complex Na2O$\mathrm{CaO}-\mathrm{ZnO}-\mathrm{PbO}-\mathrm{Fe} 2 \mathrm{O} 3-\mathrm{Al} 2 \mathrm{O} 3-\mathrm{SiO} 2$ Glasses and Glass-Ceramics" Mater. Res. Bull., 34, 1998, pp. 1107-1115.

[7] A. Karamanov, M. Pelino, G. Taglieri, C. Cantalani, "Sintered Building Glass-Ceramics Based on Jarosite", XVIII International Congress on Glass, San Francisco (USA), July 5-10, 1998, The American Ceramic Society, Ohio, M. K. Choudhary, N. T. Huff and Ch. H. Drummond III (Eds.).

[8] C. Barry Carter, M. Grant Norton, "Ceramic Materials", Springer Science+Business Media, LLC., 2007, pp.4-10.

[9] R. Brian, "Lawn Indentation of Ceramics with Spheres: A Century after Hertz", J. Am. Ceram. Soc., Vol. 81, No.8, 1998, pp. 1977-94 .

[10] R.O. Ritchie, "Mechanisms of fatigue-crack propagation in ductile and brittle solids", International Journal of Fracture, 100, 1999, pp. 55-83.

[11] P.D. Zavattieri, H.D. Espinosa, "Grain Level Analysis Of Crack Initiation And Propagation In Brittle Materials", Acta mater., 49, 2001, pp. 4291-4311.

[12] M. Suzuki, K. Ogawa, T. Shoji, "Quantitative NDE of Surface Cracks in Ceramic Materials by means of a High-Frequency Electromagnetic Wave", Materials Transactions, Vol.47, No.6, 2006, pp. 1605-1610.

[13] J.J. Kruzic, O.R. Robert, "Determining the Toughness of Ceramics from Vickers Indentations Using the Crack-Opening Displacements: An Experimental Study", J. Am. Ceram. Soc., Vol.86, No.8, 2003, pp. 1433-36.

[14] M.A. Aswad, "Comparison of the Fracture Toughness of High Temperature Ceramic measured by Digital Image Correlation and Indentation Method", Journal of Babylon University/Engineering Sciences, Vol. 22,No.4, 2014.

[15] F. Mignard, C. Olagnon, G. Fantozzi, "Acoustic emission monitoring of damage evaluation in ceramics submitted to thermal shock" Journal of the European Ceramic Society, Vol.15, No.7, 1995, pp. 651-653.

[16] K. Ito, S. Ohmata, S., K. Kobayashi, M. Watanabe, S. Kuroda, M. Enoki, "Crack Monitoring during Plasma Spraying of Ceramic Coatings by Non-Contact Acoustic Emission Method", Materials Transactions, Vol.51, No.7, 2010, pp. 1272- 1276.

[17] W.P. Ganley, "Simple pendulum approximation", Am. J. Phys. Vol.53, No.1, 1985, pp.73-76.

[18] T.C. Akinci, O. Yilmaz, T. Kaynas, M. Ozgiray, S. Seker, "Defect Detection for Ceramic Materials bey Continuous Wavelet Analysis Mechanika", Prooceedings of the 16th International Conference, 7-8 April 2011, Kaunas Lithuana, pp.9-14.

[19] R. Başar, Ü. Artan, A. Akan, "Higher-Order Evolutionary Spectral Analysis", IEEE ICASSP 6, 2003, pp. 633-636.

[20] B. Ergen, Y. Tatar, "The Bispectral Analysis of Phonocardiogram Signals", Biomedical Engineering National Meeting Biyomut Istanbul, Turkey, 2004, pp. 11-14.

[21] J.M. Nichols, C.C. Olson, J.V. Michalowicz, F. Bucholtz, "The Bispectrum and Bicoherence for Quadratically Nonlinear Systems Subject to Non-Gaussian Inputs", Signal Processing, IEEE Transactions on, Vol. 57, No.10, 2009, pp. 3879-3890.

[22] C.L. Nikias, "Higher-OrderSpectra Analysis", Prentice-Hall, Englewood Cliffs, 1993

[23] B. Jang, C. Shin, E.J. Powers, W.M. Grady, "Machine fault detection using bicoherence spectra", Instrumentation and Measurement Technology Conference, IMTC 04. Proceedings of the 21st IEEE 3 2004, pp. 1661-1666

[24] K. Han, K.R. Tinsley, J. Aguilar-Torrentera, "Identification of high speed jittered digital interconnects using bicoherence spectra", Devices, Circuits and Systems,. ICCDCS 2008. 7th International Caribbean Conference on, 2008, pp. 1- 4. 


\section{BIOGRAPHIES}

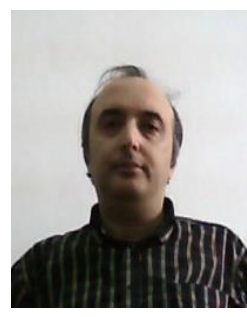

OMER AKGUN is an assistant professor at the, Department of Computer Engineering, Technology Faculty, Marmara University. He received his first $\mathrm{Ph} . \mathrm{D}$. in the Communication Engineering in 2009 from Yildiz Technical University and the second Ph.D. in the Electronic and Communication Education Department in 2011 from Marmara University. His current research interests are signal processing, biomedical signal processing, signal modelling and communication systems. 